\title{
Relações Socioambientais e Conflitos Revelados Numa Área de Manguezais em Magé - Baixada Fluminense*
}

\author{
Simone Fadel \\ Gabriel de Lima Souza \\ Jessica Damiana Pires Fernandes \\ Universidade do Estado do Rio de Janeiro
}

\section{Resumo}

O presente artigo faz uma análise das relações socioambientais numa área de ocorrência do ecossistema manguezal em Magé, município da Baixada Fluminense, situado ao fundo da Baía de Guanabara. A escolha dessa área se deu, principalmente, pelo fato do local ser palco de ações que buscam reverter problemas socioambientais como o alto índice de poluição e a disputa por terras antes usadas para a pesca artesanal e hoje dominadas pela ação de grandes empreendimentos industriais. Este trabalho conta com um breve histórico da região analisada, a fim de compreendermos através da história, fatores que possam ter levado a degradação do ecossistema em questão, para que possamos, posteriormente, dialogar comos conflitos revelados, como os movimentos sociais e a ação de iniciativa do reflorestamento, como a que vem ocorrendo atualmente no local. Trata-se de uma pesquisa realizada junto ao Núcleo Interdisciplinar de Estudos do Espaço da Baixada Fluminense (NIESBF), grupo de pesquisa cadastrado no CNPq, formado por docentes e discentes que têm como fim o estudo do espaço da Baixada Fluminense, onde se situa a Faculdade de Educação da Baixada Fluminense (FEBF), uma unidade acadêmica da Universidade do Estado do Rio de Janeiro (UERJ).

\footnotetext{
* Este texto é uma compactação e revisão do artigo Caracterização das relações socioambientais numa área de reflorestamento de manguezais no município de Magé - RJ, apresentado originalmente no V Seminário Brasileiro Sobre Áreas Protegidas e Inclusão Social (V SAPIS) realizado em Manaus, entre os dias 16 e 19 de novembro de 2011.
} 


\section{Manguezais: Berçário de espécies, Riqueza e Complexidade}

Conhecido por ser local de encontro do ambiente terrestre com o marinho, o ecossistema manguezal também é lembrado devido sua riqueza e complexidade. Além disso, ali ocorre a reprodução, o berço e criadouro de muitas espécies da fauna marinha e algumas terrestres. $\mathrm{O}$ contato com as marés, fundo de baías e estuários de rios, faz com que os manguezais tenha um aspecto úmido, de encontro da água doce e da salobra, passando maior parte do tempo inundado. Trata-se de um ecossistema facilmente identificado por um solo de substrato mole, resultante de um processo que se dá do acumulo dos sedimentos trazidos pelos rios e que misturados á água salobra, cuja presença é fundamental para sua caracterização, irão apresentar esta característica. Encontramse em áreas de temperatura média e climas tropicais e subtropicais em aproximadamente 112 países ao longo do planeta. Aproximadamente $35 \%$ dos manguezais do planeta são encontrados encontram-se na América do Sul, desses, 2,5 milhões de hectares estão no Brasil. De acordo com Lacerda (1999), os manguezais brasileiros estão distribuídos na costa do país, desde o rio Oiapoque, no estado do Amapá (latitude $4^{\circ} 30^{\prime} \mathrm{N}$ ), à praia do Sonho, litoral catarinense (latitude $28^{\circ} 53 \mathrm{~S}$ ), apresentando bastante variedade entre eles.

A caracterização dos manguezais irá variar, de forma que o mesmo pode ser encontrado em diferentes regiões do planeta cuja condições naturais irão fazer com que haja essa variação. $\mathrm{O}$ nome manguezal origina-se da árvore típica do ecossistema, o mangue. Trata-se de uma espécie de planta halófita, que mesmo terrestre adapta-se ao ambiente marinho, tornando-se tolerante ao grau de salinidade. Segundo Serrel os mangues:

\footnotetext{
“...embora parcialmente imersos em meio aquático, apresentam adaptações normalmente associadas às plantas dos desertos, que ajudam a reduzir a quantidade de água perdida pela planta, não só em função das altas temperaturas como ainda em virtude dos efeitos secantes da água salgada.” (Serrel, 1975, apud Sant'anna e Wharely, 1981, p.48)
}

Entre os principais tipos de mangue encontrados temos a Rhizophora mangle e a Avicennia $s p$, as quais são as únicas espécies presentes em diferentes regiões do planeta. São plantas resistentes, com galhos retorcidos, e que apresentam uma variação em seu tamanho, que vai depender da região na qual será encontrada. Suas folhas são coriáceas, caracterizadas por evitar a transpiração, e suas raízes são aéreas, que permitem uma absorção significativa de oxigênio.

Segundo Amador(1997) o ecossistema manguezal possui uma estrutura física que irá permitir que diferentes espécies de animais o utilizem aquela área como abrigo. A fauna do manguezal conta com diferentes espécies de peixes, aves, crustáceos, moluscos, que passam toda ou pelo menos uma parte da vida naquele ambiente. A fauna dos manguezais pode ser agrupada em 
quatro grupos funcionais distintos: aqueles que estão associados à vegetação de mangue, como o caso de alguns pássaros que utilizam a copas das árvores com habitação, as espécies visitantes, os que habitam as áreas por um curto período de tempo e que contam em sua maioria por mamíferos, as espécies marinhas, que passam apenas uma parte de suas vidas nos manguezais, caso de alguns peixes, e por fim as espécies residentes, como crustáceos, como cracas e caranguejos e moluscos como ostras e caramujos (Lacerda, 1999). Dentre as espécies residentes, os caranguejos são os mais conhecidos e são ainda hoje sustento de muitas famílias e catadores que vivem da caça predatória.

\section{Manguezais na Baixada Fluminense: Sobreviventes de uma História de Devastação}

Muito já se conhece sobre a devastação pela qual vem sofrendo os sistemas naturais brasileiros. A Floresta Amazônica e o Cerrado são vítimas notáveis do desmatamento, e os números quando ao índice de destruição tem sido cada vez mais preocupante. Outro caso de extrema relevância no Brasil é o da Mata Atlântica, que desde o período colonial tem sua cobertura vegetal sofrendo ameaças e hoje é um dos biomas mais ameaçados do mundo. Muitos estudos sejam eles de historiografia tradicional ou sob o viés da história ambiental, nos revelam essa situação, conforme os trabalhos de Warren Dean $^{1}$ e de José Augusto Drummond ${ }^{2}$. Neles, podemos compreender melhor as ações de impactos causados pelos portugueses no início da colonização do país, que nos primeiros anos foi marcado pela retirada de Pau Brasil, seguindo nos períodos posteriores para o uso da terra na plantação de cana de açúcar e nos anos seguintes, café. Não podemos deixar de explicitar que a evolução urbana também contribuiu para a retirada da floresta, à medida que aqueles espaços naturais aos poucos iriam dando lugar a moradias, prédios comerciais e

1 Warren Dean destaca-se por seus estudos da história ambiental da Mata Atlântica fazendo um trabalho muito minucioso e interessante no livro intitulado "A Ferro e Fogo: a história e a devastação da Mata Atlântica brasileira” de 1994. Nele, o autor busca não fazer uma mera análise de história natural da Mata Atlântica, ou seja, uma simples observação de suas características e espécies, mas sim fazer um estudo da relação do homem com a floresta ao longo da história.

2 Dentre as obras escritas por Drummond podemos destacar o livro "Devastação e Preservação Ambiental no Rio de Janeiro", no qual o autor descreve uma visão que grande parte da população brasileira tem acerca das belezas naturais do Estado do Rio de Janeiro. É inegável o número de paisagens como as praias e florestas presentes no estado, porém pouco se fala do quanto essas "belezas" atuais vieram sofrendo uma significativa degradação imposta pelo ser humano. Drummond destaca o quanto no Brasil, falar de devastação florestal está apenas vinculado a Amazônia, quando uma significativa quantidade da rica Mata Atlântica aqui existente que aqui existia desde período pré cabralino já foi destruída. 
outras construções que acompanhavam a dinâmica da expansão urbana.

Não muito diferente do bioma Mata Atlântica, os manguezais também sofreram impactos, seja por interesses econômicos, visto que fornecia madeira, fauna destinada à pesca e a catação de crustáceos, ou pelo avanço das cidades, que levavam a aterros e dissecações. O Brasil abriga grandes sítios arqueológicos que comprovam a utilização desse ecossistema desde os povos antigos, como o caso dos sambaquis, os quais deixaram vestígios em algumas áreas do Rio de Janeiro, inclusive na Baixada Fluminense ${ }^{3}$. Para Abreu, os manguezais são:

"Verdadeiros viveiros de crustáceos e de outros organismos vivos (...) e tiveram sua importância atestada por diversas pesquisas arqueológicas, que resultara, o papel fundamental que sempre exerceram para a ocupação humana do recôncavo da Guanabara.” (Abreu,2010,p. 342).

A literatura que trata da ocupação das terras da região ora denominam mangue, ora pântano e ainda brejo para as áreas alagadas, causando uma certa dificuldade para o entendimento sobre o papel do mangue e sua devastação e utilização ao longo desta história de ocupação. Lamego (1948) denomina brejo uma vasta área da Baía e do entorno dos principais rios do chamado Recôncavo que foram ocupados com engenhos.

"Tornando-se difícil o caminhar pelos bordos da baía, devido a tanto brejo, tinha entretanto o carioca admiráveis estradas naturais pra a sua grande obra civilizadora nos sistemas de rios que da Guanabara se irradia em leque para as zonas montanhosas. Todos decisivamente influíram na penetração. Pelas águas do Meriti, do Sarapuí, do Iguaçú, Do Pilar,(...) do Majé (...) é que foram subindo os desbravadores, Ao longo de suas margens é que foram alinhando engenhos e fazendas e por eles é que descia para o Rio de Janeiro a produção agrícola do recôncavo.” ( Lamego, 1948, p.135)

No campo da Geografia Histórica do Rio de Janeiro, Abreu (2010) destaca que nas áreas dos antigos engenhos fluminenses, o século XVII foi espaço de disputas que envolviam o direito à pesca, ao acesso e aos limites às terras livres para a pesca. Utilizando uma riqueza de fontes primárias do período, o autor relata que:

"Para garantir o piraiquê, era necessário que a Câmara redobrasse sua atenção sobre a atividade dos pescadores, razão pela qual editou, durante o século XVII, uma série de posturas que instituíram o defeso nos meses de junho e julho. (...) Barra adentro, a ação

3 A Baixada Fluminense é uma região desenvolvida entre o sopé da Serra do Mar e o Oceano, interrompida por colinas e maciços costeiros e adquiriu durantes os séculos passados diversas funções desde as atividades rurais como plantação de cana, café até a citricultura e posteriormente os loteamentos. É atualmente por treze municípios: Duque de Caxias, Nova Iguaçu, São João de Meriti, Nilópolis, Belford Roxo, Queimados, Mesquita, Magé, Guapimirim, Japeri, Paracambi, Seropédica e Itaguaí. Estes municípios são considerados como parte da região metropolitana do Rio de Janeiro (núcleo metropolitano), e de acordo com o Centro de Informações e Dados do Estado do Rio de Janeiro (CIDERJ) há também uma regionalização histórico-cultural que se baseia na formação social da área (história da conquista, ocupação e evolução social e econômica). Fonte: Biblioteca Virtual do Meio Ambiente da Baixada Fluminense. 
edilidade se concentrava sobre os proprietários das ilhas e terrenos lindeiros à Baía (...). Isso ocorria, sobretudo nas áreas de manguezais e foi para garantir a natureza comunal desses alagadiços à beira-mar.” (Abreu, 2010 p. 343).

Ainda segundo Abreu, apesar da utilização intensa das espécies da flora do mangue para construção e lenha, o mangue no início da colonização não se apresentava como uma terra de grande interesse. Uma terra alagada e imprópria para a agricultura não apresentava condições de competir com a fartura de terra firme.

Apesar da valorização da madeira do mangue ter sido identificada já no Século XVI, ainda encontraremos este ecossistema presente com relativa abundância até meados do século XIX. Neste período a atuação da Diretoria de Saneamento da Baixada Fluminense nos rios da região se constituirá como um fator preponderante no impacto aos manguezais. A passagem que se segue do relatório elaborado pelo Engenheiro Hildebrando de Góes apresentasse como um relato importante pelo registro da permanência de vastos manguezais na Baixada neste período. Além disso, demonstra claramente uma visão da necessidade de superação deste ecossistema para a presença de “vida" na região. A Baixada dos mangues é a baixada do impaludismo e "inacabada para a vida".

\begin{abstract}
"Excepcionalmente, o recôncavo da Guanabara teve gênese diversa. (...) Forma-se, assim, ao longo da costa e de cada lado dos rios, extensas áreas periodicamente alagadas pelas marés, que o manto das risoforas recobre. Quando transbordam os cursos d'água, os materiais sólidos, em suspensão, depositam-se nos terrenos baixos que os marginam. E os manguezais, que se prolongam até o mar, elevam-se sem cessar, transformando-se nas vastas planuras que orlam a baía suntuosa.Na baixada inteira o solo como que se alça á nossa vista, numa lenta emersão. Colmatam-se, pela ação dos agentes naturais, lagoas e brejais, mangues e alagadiços. (...) A terra enxuga-se aos poucos. Mas permanece ainda, inacabada para a vida. (grifos nossos)" ( Góes, 1939, p.12)
\end{abstract}

Uma história ambiental deste ecossistema na região da Baixada Fluminense ainda está por se constituir e aqui se apresentou apenas breves pontos que reafirmam a importância desta tarefa. Nosso propósito com os relatos aqui apresentados foi o de reafirmar que os mangues hoje encontrados na região da Baixada Fluminense são verdadeiros sobreviventes de um história de devastação. Se por um lado, o mangue apresenta um terreno mais difícil para o acesso e que a mata atlântica da região, por outro, sua dinâmica hídrica é profundamente afetada pela retificação dos rios, ocorrido na atuação das Comissões de Saneamento e da Diretoria de Saneamento da Baixada fluminense. O mangue é então "vencido" pelo ressecamento ou mudança no grau de salinidade e sua vegetação derrubada com relativa facilidade. Como veremos a seguir, a constituição do município de Magé não foge ao binômio ocupação- devastação do manguezal. 


\section{O Município de Magé: Características Históricas, Físicas e Sociais}

Dados históricos revelam que a cidade de Magé surge entre os mangues e alagados do fundo da Baía de Guanabara com o propósito inicial de povoar a região. No século XVII, escravos e trabalhadores são levados a região próxima ao Rio Magepe Mirim, por Simão Mota, que após sua contribuição na luta contra os franceses no Rio de Janeiro, recebe a primeira sesmaria da área, que hoje compreende a atual cidade de Magé. O local continuou sendo palco de distribuição de outras sesmarias e com o aumento do povoamento dessa região ela se eleva posteriormente em 18 de janeiro de 1696 a freguesia.

Com o contínuo aumento da população, se desenvolve perto da praia de Ipiranga outro povoado, que recebe o nome de Povoado de Pacobaíba, em virtude da construção da Igreja Nossa Senhora de Pacobaíba. Em 1775, a região também torna-se freguesia perpetua, assumindo o nome de Guia de Pacobaíba, hoje conhecida também como Praia de Mauá. Com o passar dos anos cerca de outras nove áreas estavam tornando-se freguesia, e em 1789, a freguesia chamada Nossa Senhora da Piedade de Magé, acaba elevando-se a vila, devido ao grande aumento do povoado e das atividades ali desenvolvidas. No mesmo ano a vila recebe uma câmara pública e uma cadeia, e aos poucos começa a se tornar responsável pelas cobranças de impostos na região.

Em 20 de maio de 1846 o Arraial de Estrelas composto pelas freguesias de Guia de Pacobaíba e Inhomirim, que foi desmembrado da vila de Magé, também é elevado à vila. Com a necessidade de um novo caminho para o escoamento do ouro que vinha sendo produzido por Minas Gerais, alguns estudos apontam que essa região seria ideal para a construção desse novo caminho, que ligaria o rio Paraíba do Sul ao Porto Estrela, facilitando o escoamento do ouro. Essa mesma região recebe em 1854 a primeira Estrada de Ferro da América do Sul, marco da região lembrado até os dias de hoje. A localização estratégica da área permitiu a construção da ferrovia em Fragoso, na atual Mauá, área que facilitava a ligação da Corte com o Porto Estrela. Com os ganhos dessa região, sua importância econômica e ainda o bom olhar da corte em virtude da Estrada de Ferro, em 2 de outubro de 1857, Magé é elevada a cidade. Em 1911, o município era constituído de seis distritos: Magé, Guia de Pacobaíba, Inhomirim, Santo Aleixo, Suruí e Guapimirim. Este último tornou-se município independente em 21 de dezembro de 1990, através da lei estadual $\mathrm{n}^{\circ} 1772$.

Segundo dados do Instituto Brasileiro de Geografia e Estatística (IBGE), Magé possui hoje cerca de 27.000 habitantes, distribuídos numa área de 385,696 km² (figura 1), a qual está divida em seis distritos ( Centro, Santo Aleixo, Rio do Ouro, Suruí, Guia de Pacobaíba e Vila Inhomirim). Em geral, apresenta alguns problemas de ordem social, política e econômica refletidas diretamente na população local, que sofre com falta de estruturas básicas, como tratamento de esgoto e água canalizada, fato que atinge desde a população pobre até as de maiores rendas. A política local foi 
marcada por escândalos envolvendo os principais detentores do poder em denúncias de corrupção.

Regiões como a de Guia de Pacobaíba, são banhadas pela Baía de Guanabara, o que faz com que Magé apresente belas paisagens naturais. Apesar de problemas como a poluição, muitas pessoas ainda visitam as praias e cachoeiras do município, assim como as igrejas e festas tradicionais como a ocorrida em Santo Aleixo, que atraem turistas para o local. As regiões litorâneas de Magé, também são altamente conhecidas pela pesca que é praticada durante todo o ano, e que também sofre com as questões da poluição. Acerca desta questão, descreveremos melhor ao tratarmos das lutas dos pescadores contra essas injustiças ambientais.

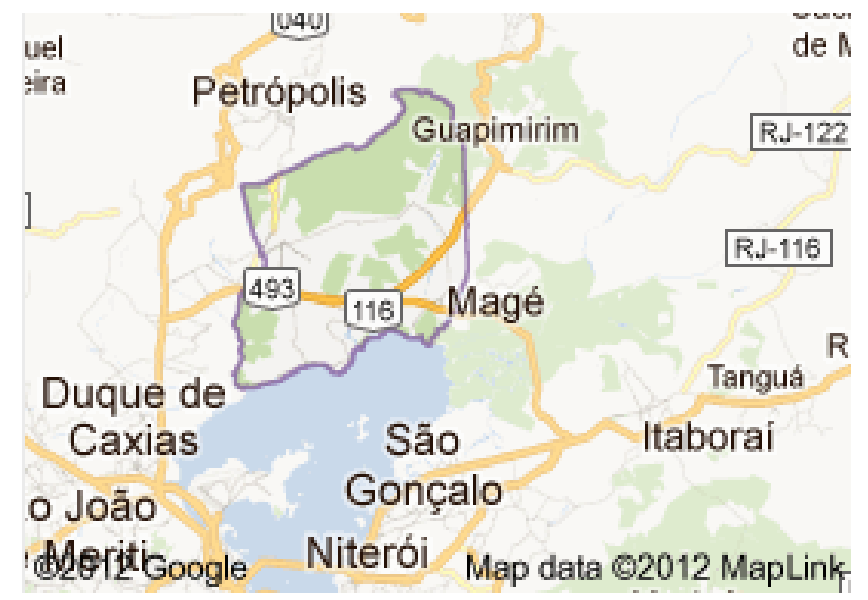

Figura 1: Localização do Município de Magé - RJ (Fonte Google Maps, 2012).

\section{Os Desafios Atuais dos Manguezais de Magé}

Os manguezais brasileiros encontram-se ao longo da costa nacional, dos quais $85 \%$ estão no litoral norte, entre os estados do Amapá, Maranhão e Pará, 10\% do Ceará ao Rio de Janeiro, e 5\% do Rio de Janeiro a Santa Catarina. Nessa última área, segundo Lacerda (1999), os manguezais apresentam-se mais complexos do que o restante do Brasil, sendo restritos aos fundos de baía, como é o caso da Baía de Guanabara, no Rio de Janeiro. Da região Sudeste do Brasil, o entorno da Baía de Guanabara, área que compreende os municípios da, apresenta as maiores faixas de remanescentes de manguezais, concentrados entre os municípios de Guapimirim, Magé, Itaboraí e São Gonçalo, os quais em 2010, $85 \%$ representavam os preservados pela APA de Guapimirim (Pires, 2010). Entre Magé e Guapimirim podemos encontrar espécies de Mangue Branco (Laguncularia racemosa), Mangue Vermelho (Rhizophora mangle), e o Mangue Negro (Avicennia $s p$ ), em estatura regular, pois de acordo com Lacerda (1999), as árvores do litoral sudeste raramente ultrapassam $10 \mathrm{~m}$ de altura, enquanto árvores de Rhizophora mangle encontradas no litoral norte podem chegar a $1 \mathrm{~m}$ de diâmetro e até $40 \mathrm{~m}$ de altura. Na fauna destacamos os caranguejos do tipo 
Uçá, Aratum e Chama-maré; aves como a Garça branca, garça cinza, beija-flor, quero-queros; além de espécies de invertebrados como os camarões e as diversas espécies de borboletas.

Os manguezais, que não pertencem aos limites da APA de Guapimirim, encontram-se em estado crítico, neste caso os manguezais da área de nosso estudo, a cidade de Magé. Ainda que protegido por leis nacionais ${ }^{4}$, as porções do ecossistema encontradas na área são vítimas de poluição e devastação. O fato de o município situar-se ao fundo da Baía faz com que chegue ali diariamente uma quantidade significativa de lixo, produtos químicos e lixo orgânico. Podemos destacar também as áreas desse ecossistema encontradas na divisa com a cidade de Duque de Caxias, próximo às bacias dos rios Estrela, Inhomirim e Iguaçu, pois são elas vítimas de contaminação química e implantação de dutos, devido à proximidade com a Refinaria de Petróleo de Duque de Caxias (REDUC ${ }^{5}$ ). É importante ressaltar que nessas áreas marcadas pela devastação, o solo acaba apresentando-se em péssimas condições, com pouca inundação e alto grau de salinidade, o que não permite a adaptação das plantas. A fim de amenizar essas situações, iniciativas vêm sendo tomadas em Magé, dentre as quais podemos destacar a criação de Áreas de Proteção Ambiental (APA), como é o caso da APA Suruí e da APA Estrela, integralmente situada no município.

De acordo com o Plano de Manejo da APA Estrela, o manguezal é a mais importante formação ao longo de seus $35,9 \mathrm{~km}^{2}$ de área, os quais ocupam o entorno do Rio Estrela até seu encontro com a Baía de Guanabara. Através do Programa o Mangue é Nosso, a APA busca dentre outras ações, conscientizar a população que freqüenta a região acerca da importância do ecossistema manguezal, ministrando palestras sobre questões ambientais, visitas as áreas recuperadas e projetos de educação ambiental.

4 Os Manguezais no Brasil são considerados na Lei 4.771 de 15 de setembro de 1965 como Áreas de Preservação Permanente (APP). Além disso, conforme consta na Resolução CONAMA N. ${ }^{o} 369$ de 28 de março de 2006, as áreas onde se encontram o ecossistema não podem sofrer supressão de sua vegetação ou qualquer tipo de intervenção, salvo em casos de utilidade pública.

5 Dentre os acidentes ambientais mais impactantes na Baía de Guanabara, destaca-se o vazamento de 1,3 milhão de litros de óleo, ocorrido em janeiro de 2000. Danos muito graves foram causados aos manguezais, as praias e à população de pescadores. Mais de uma década depois do ocorrido, quando a Refinaria completou 50 anos de existência, foi realizado em Duque de Caxias o seminário "50 anos de REDUC: Ganhos, Perdas e Danos", que buscou trazer discussões acerca dos problemas e das mudanças que vem sendo ocorrendo na região onde funciona a Refinaria ao longo desses anos. O seminário contou com parcerias entre a Universidade do Estado do Rio de Janeiro, a Universidade Federal do Rio de Janeiro, o Sindicato dos Petroleiros de Duque de Caxias, a Rede Brasileira de Justiça Ambiental, a Associação Homens do Mar, entre outros. As mesas de debates eram compostas por pesquisadores, representantes de sindicatos, associação de moradores e pescadores, e nelas haviam diferentes temáticas, entre elas a "REDUC e a Baía de Guanabara", mesa na que foram abertas várias discussões sobre o meio ambiente, poluição e o ecossistema manguezal. 
Outra atividade que busca fazer-nos refletir quanto à importância e preservação dos manguezais pode ser exemplificada por projetos de reflorestamento desse ecossistema que foram criados na região. O município de Magé atualmente conta com dois projetos: um desenvolvido pela Petrobrás, próximo às áreas afetadas pela contaminação de 2000 e o Projeto Mangue Vivo, iniciativa da Fundação OndAzul, que segundo o Plano de Manejo da APA Estrela é o maior projeto de recomposição de mangue do Brasil.

Nascido a partir da Organização Não-Governamental Fundação OndAzul, o projeto vem ao longo de mais de uma década de existência atuando no bairro do Ipiranga, tendo como foco transformar uma área marcada por lixo, lama e esgoto, numa paisagem verde, na qual a flora e a fauna possam viver em harmonia com moradores locais e até pessoas que ali circulam no sentido de fazer visitação. Mesmo diante de obstáculos que dificultam as atividades realizadas pelo projeto, desde problemas político-burocráticos, perda de área originalmente destinada ao replantio até o grande desafio da poluição, o projeto tem conseguido dar a volta por cima e conta com resultados positivos. São cerca de 38mil mudas de mangue plantadas até hoje, numa área de 12 hectares recuperada, que forma uma jovem floresta de mangue e que vem permitindo o retorno da fauna aos locais, que antes era impossibilitada de viver ali devido à degradação ${ }^{6}$

A região de Guia de Pacobaíba, tem sido ainda uma das áreas de abrangência de movimentos e reivindicações de pescadores que lutam por maior liberdade e preservação das áreas das quais tiram seu sustento. O entorno da Baía de Guanabara conta com cerca de 22 mil pescadores artesanais, organizados em 5 colônias. Muitos desses sofrem com a pobreza e o desemprego, gerados entre outros fatores pela poluição ambiental das áreas de pesca. Após o derramamento de óleo na Baía de Guanabara em 2000, as lutas dos pescadores foram se intensificando, motivando a criação da fundação do Grupo Homens do Mar, que posteriormente se tornaria a Associação dos Homens da Baía de Guanabara (AHOMAR). Na tentativa de ganhar voz para sua luta, a AHOMAR articula-se com ONGs ambientalistas, associação de moradores, para levar ate a mídia suas dificuldades e buscar melhorias. Uma das ações mais eficientes, realizada pela AHOMAR ocorreu na área de pesca na Praia do Imperador, no qual os pescadores receberam informações de que a empresa GDK estava trabalhando na construção dos gasodutos dos projetos da PETROBRAS, o que os levaram a ocupar o canteiro de obras. Contudo, as informações dessa ação vazaram e a estratégia mudou, levando os pescadores a realizar uma assembléia no mar onde decidiram impedir o atracamento da barca Rio - Paquetá. Essa ação alcançou seu objetivo, sendo noticiada na

6 Os autores do presente artigo visitaram o Projeto Mangue Vivo no dia 24 de maio de 2011. Algumas das informações aqui presentes são resultantes da fala de alguns dos envolvidos no projeto, que estavam no local na data da visita. Outros dados foram concedidos aos autores através de materiais escritos e audiovisuais de divulgação da Fundação OndAzul, assim como os próprios dados disponíveis no site oficial da ONG ( http://www.ondazul.org.br ). 
televisão, porém a repressão da policia foi violenta, com helicópteros e armas apontadas para os pescadores. Após essa repressão, foi decidido apenas realizar assembléia no mar, para tentar que apenas os pescadores de verdade participassem. Outras ações foram sendo orquestradas, e novas alianças foram sendo formadas, como por exemplo, a articulação com a Rede Brasileira de Justiça Ambiental $^{7}$.

\section{Conclusão}

Por fim, os manguezais encontrados na área de estudo revelam uma degradação que vem ocorrendo ao longo dos anos e que modificaram muito a composição original desse ecossistema. Podemos perceber que as iniciativas de reflorestamento assim como os movimentos sociais por parte dos pescadores, aumentam a interlocução entre sociedade e natureza, possibilitando assim uma maior conscientização por parte da população sobre a preservação daquele ambiente. A articulação destas ações se constituem como um ponto fundamental.

Acreditamos que o desenvolvimento de propostas de Educação Ambiental na área são importantes, de forma que possam trazer aos viventes do entorno um pensamento crítico sobre as questões de impactos e utilização sustentável do ecossistema, bem como de suas condições de vida. E como apontamos anteriormente, um estudo sobre a história ambiental do ecossistema manguezal faz-se, também, necessário como forma de contribuir para o um maior entendimento com a situação atual, bem como encontrar canais de interlocução entre a história ambiental do mangue no processo de ocupação local e os impactos vivenciados atualmente. A população local, em especial a população de pescadores, recoloca e refaz cotidianamente sua história em articulação com este ecossistema e esse resgate é fundamental para percebermos os limites e as possibilidades das relações que se estabelecem atualmente nos e com os manguezais locais.

7 Com o crescimento do movimento e o aumento da sua visibilidade, as ameaças a seus principais lideres aumentaram, vários ataques e tentativas de assassinatos foram registrados por integrantes da AHOMAR, culminando no assassinato do tesoureiro da Associação no dia 29 de maio de 2009. Esse crime ainda encontra-se sem solução. O atual presidente dessa associação é obrigado desde 2009 a andar com uma escolta armada durante 24 horas, para sua proteção e de sua família. 


\section{Referências Bibliográficas}

ABREU, Mauricio de Almeida. Geografia Histórica do Rio de Janeiro - Parte II Rio de Janeiro: Instituto Pereira Passos (IPP)/ Editora Andrea Jacobsen, 2010. p.342 - 345.

AMADOR, Elmo da Silva. Baía de Guanabara e ecossistemas periféricos: homem e natureza.

Rio de Janeiro: E. S. Amador, 1997.

Biblioteca Virtual do Meio Ambiente da Baixada Fluminense, disponível em <www.bvambientebf.uerj.br>, acessado em 15 de Fevereiro de 2012.

IBGE Cidades - Magé - RJ disponível em < http://www.ibge.gov.br/cidadesat/>, acessado em 10 de Janeiro de 2012.

LACERDA, Luiz Drude de. Os manguezais do Brasil. In: Os manguezais e nós: uma síntese de percepções. Marta Vannucci (org.) São Paulo: Edusp, 1999, p. 193 - 205.

PIRES, Ivan Oliveira. Manguezais da Região do recôncavo da Baía de Guanabara: revista através dos mapas. In: Revista da Gestão Costeira Integrada - Número Especial 2, Manguezais do Brasil. Portugal, 2010.

PRADO, Walter de Oliveira. História da Baixada Fluminense: das Sesmarias a Foros da Cidade. Rio de Janeiro: EcoMuseu Fluminense, 1964.

PREFEITURA MUNICIPAL DE MAGÉ - SECRETARIA MUNICIPAL DE TURISMO E MEIO AMBIENTE. Plano de Manejo da Área de Proteção Ambiental Estrela. Magé (RJ), 2010.

SANT'ANNA, Edna Mascarenhas / WHATELY, Maria Helena Distribuição dos manguezais do Brasil. In: Revista Brasileira de Geografia - Rio de Janeiro. ano43 nº1, 1981, p. 47 - 64. 